\title{
El dilema de los híbridos sociales como alternativa de producción.
}

\author{
El caso del transporte ferroviario de pasajeros del área metropolitana \\ de Buenos Aires (2003- 2015)
}

The dilemma of the hybrid as a social production alternative. The case of passenger's railway transport in the Greater Buenos Aires Metropolitan Area (2003 2015)

Verónica Pérez

CONICET-IDAES/UNSAM; IIGG/UBA

veronikaperez@gmail.com

Fecha de recepción:

23.11.15

Fecha de aceptación:

11.3.15

\section{Resumen}

La historia reciente de los ferrocarriles metropolitanos de pasajeros se caracteriza por la implementación de sucesivas transformaciones en las formas sociales de organizar su prestación. Las mismas han tenido como común denominador un creciente protagonismo del Estado en la actividad, con resultantes heterogéneas que dificultan un balance positivo de la etapa. La hipótesis propuesta es que una de las principales condiciones que permiten comprender esta situación radica en la configuración de una particular relación entre Estado, empresarios y sindicalismo empresario, que ha sido conceptualizada como simbiosis colusiva. El período comprendido en este estudio inicia en 2003 y finaliza en 2015.

Palabras clave: ferrocarriles metropolitanos - estado - empresarios - sindicatos - transporte de pasajeros.

\section{Abstract}

The recent history of the Metropolitan passenger's railway transportation is characterized by the enactment of successive transformations in the social organization of its provision. They have as a common denominator a growing importance in the state's involvement, with heterogeneous results that make it difficult to sustain a positive balance the experiences. The hypothesis sustaining the present work assesses that in order to understand the cur- 
rent problematic, focus has to be shed on the build-up of a particular relationship between the state, entrepreneurs and corporate unionism, which is characterized as a case of collusion symbiosis. The period covered by this study begins in 2003 and ends in 2015.

Key-words: metropolitan railroads - state involvement - business people - unions - passengers' transportation

\section{Introducción ${ }^{1}$}

La entrada al nuevo milenio significó para los ferrocarriles metropolitanos de pasajeros en Argentina la profundización de su deterioro, en el marco de una crisis social, económica y política sin precedentes. No obstante el mejoramiento progresivo que lentamente fue evidenciando la situación general del país, esta no impactó en los principales indicadores de calidad de los servicios.

Concomitantemente a la revalorización del rol del Estado en la economía, se sucedieron recurrentes transformaciones en las formas sociales de organizar la prestación de los servicios; sin embargo la persistencia de lógicas de acumulación de poder que atravesaron al sistema, lo convirtieron en un espacio sometido a perturbaciones de diversas clases. Demoras, cancelaciones, accidentes con víctimas fatales y expresiones de disconformidad protagonizadas por pasajeros, constituyeron rasgos sobresalientes del período. Estas perturbaciones propiciaron una progresiva mayor intervención del Estado en la actividad, cuyo corolario fue la asunción de funciones empresariales mediante el control pleno de una línea de servicios en el año 2013 (línea Sarmiento) y luego de otras cuatro líneas (San Martín, Belgrano Sur, Roca y Mitre), de las siete que integran la red metropolitana de ferrocarriles de pasajeros. El creciente avance estatal en la actividad concluye en abril de 2015, con la aprobación parlamentaria de la Ley de Ferrocarriles Argentinos $\left(N^{\circ} 27.132\right)$ que devuelve al Estado un protagonismo central sobre su gestión.

La historia reciente en las formas sociales de organizar la prestación de los servicios ferroviarios metropolitanos convoca a una serie de interrogantes: ¿Dónde radican las principales dificultades que ha mostrado el sistema en los últimos años? ¿En qué medida las progresivas intervenciones del Estado en la actividad generaron la posibilidad de superar las deficiencias existentes en los servicios? ¿Cuáles son las enseñanzas que deja esta breve pero convulsionada historia reciente en la administración de los ferrocarriles de pasajeros del Área Metropolitana de Buenos Aires? 
Este trabajo se sitúa en el enfoque de sistemas complejos desarrollado por Rolando García (2006). Esta perspectiva teórico-metodológica se basa en identificar las principales relaciones estructurantes de los sistemas, a los fines de dar cuenta tanto de sus características generales como de sus tendencias de desarrollo. El estudio se complementa con los aportes del enfoque neomarxista desarrollado por Erik Olin Wright (2006, 2010), en torno a las características de los modelos híbridos de organización de la producción de bienes y servicios y con las contribuciones de algunos de los estudiosos de las relaciones entre Estado y empresarios, nucleados en lo que hoy se conoce como la nueva sociología del desarrollo (Amsden; 1989, Evans; 1996).

El artículo se divide en seis secciones. En la primera, se introduce sucintamente la orientación del gobierno iniciado en 2003 hacia las empresas privatizadas en la década precedente. Seguidamente se analiza la orientación estatal en la actividad ferroviaria de pasajeros en el nuevo gobierno, destacándose el derrotero de sus principales indicadores de calidad. En la tercera se describen las principales transformaciones en las formas sociales de organizar la prestación de los servicios ferroviarios entre 2003 y 2012, proponiendo distintos niveles de procesos como clave explicativa para entender dichos cambios y sus resultantes sobre el sistema. La cuarta sección tiene por objetivo conceptualizar el carácter dominante que asumió la lógica de prestación de los servicios tras las transformaciones abordadas en el apartado anterior, proponiendo como hipótesis la existencia de una simbiosis colusiva entre funcionarios del Estado, empresarios y sindicalismo empresario. La quinta sección analiza las resultantes de dicha lógica sobre la calidad de los servicios, mientras la sexta aborda cronológicamente el avance estatal sobre la operación del sistema post 2012. Para terminar, se presentan unas breves conclusiones a modo de reflexión final.

Los argumentos que aquí se desarrollan se sostienen en el análisis de fuentes primarias y secundarias. Entre ellas destacan estudios específicos sobre la temática, documentos oficiales, información de prensa, indicadores de calidad sobre los servicios provistos por organismos públicos, evolución del monto de los subsidios al sector y entrevistas a informantes clave.

\section{El regreso del Estado}

El ingreso de Argentina al siglo XXI se dio en un contexto de profunda crisis de acumulación capitalista resultante del agotamiento del modelo de acumulación anclado en la valorización financiera del capital (Basualdo; 2006). La dislocación social (Polanyi; 2001) provocada por dicha crisis minó sustantivamente las bases del amplio consenso que habían logrado alcanzar buena parte de las reformas de inspiración neoliberal implementadas en la etapa precedente (Pucciarelli y Strauss; 2011, Thwaytes Rey; 2011).A partir de entonces comenzó a desenvolverse una generalizada crítica social a muchos de 
los postulados sobre los cuales las mismas se erigieron. Parte de esta crítica fue retomada desde el gobierno a partir de la apertura de un nuevo ciclo político, iniciado en 2003 con la asunción de Néstor Kirchner a la Presidencia de la Nación (Pérez y Rebón;2015).

Desde el inicio de esta nueva etapa, el clima cultural adverso a la intervención del Estado en la economía que había signado la década de los años noventa fue puesto en discusión. Dicha crítica no sólo se desenvolvió en un plano discursivo sino que tuvo su correlato en la ejecución de un conjunto de acciones materiales concretas: nuevas regulaciones, subsidios, créditos, fomento a la demanda vía política salarial y social, e incluso participación directa del Estado en la producción de bienes y servicios (Pérez y Rebón; 2015). Si bien no existe consenso en torno a la caracterización de esta nueva etapa, difícilmente pueda dudarse de un cambio de ciclo en torno al "corazón de las reformas" (Costa; 2000) de la década precedente: la privatización de empresas públicas.

El nuevo ciclo político incluyó desde el inicio un replanteo de las relaciones del Estado con las empresas que habían sido privatizadas durante la etapa de auge neoliberal (Azpiazu; 2005). En un contexto de cambio de paradigma, las consecuencias negativas de muchas de las privatizaciones realizadas en la década precedente tuvieron como respuesta un pedido de "retorno del Estado" que incluyó, en su progresivo desarrollo, una serie de re-estatizaciones de empresas bajo un amplio abanico de lógicas de acción (Pérez y Rebón; 2015). La intervención del Estado en la actividad ferroviaria no fue ajena a estas tendencias.

\section{La orientación del Estado en la actividad ferroviaria de pasajeros del Área Metropolitana de Buenos Aires posterior a 2003}

Como rasgo general, la gestión del nuevo gobierno -en lo que a los ferrocarriles metropolitanos respecta-, estuvo atravesada por los efectos derivados de la Emergencia Ferroviaria (decreto 2075/2002) heredada del gobierno de transición de Eduardo Duhalde (2/1/2002-25/05/2003). Dicha medida significó para los ferrocarriles metropolitanos el colapso de sus principales indicadores de calidad, así como un profundo agravamiento de la seguridad del sistema. A partir del hito referido, la puntualidad de los servicios empeoró progresivamente y si bien evidenció una leve mejora entre los años 2008 y 2010 , no logró alcanzar el registro que había mostrado a inicios del ciclo analizado. A partir de 2010 dicho indicador volvió a derrumbarse hasta alcanzar el peor desempeño del período. Por su parte los descarrilamientos -elocuente indicador de los efectos derivados de una gestión privada cuya rentabilidad estuvo basada principalmente en el recorte de gastos de mantenimiento-, pasaron de 18 a 63 en apenas dos años (2005-2007); aunque revelaron una tendencia a la baja en el mismo período que el indicador anterior, volvieron a incrementarse hasta superar el momento de su peor desempeño. 


\section{Grafico $N^{\circ} 1$}

Evolución de la puntualidad de los servicios y de los descarrilamientos. Total red metropolitana de transporte ferroviario de pasajeros. 2002-2012.

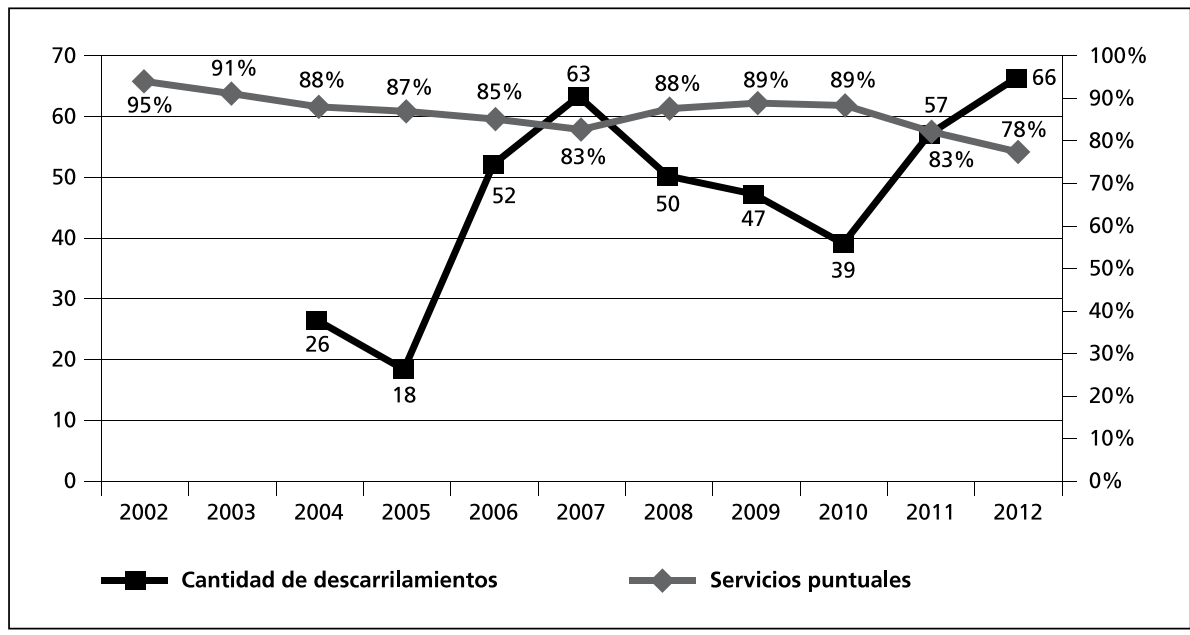

Fuente: Elaboración propia con base a datos de la Comisión Nacional de Regulación del Transporte (CNRT) 2015

En la hipótesis de este trabajo la Emergencia Ferroviaria vino a profundizar y a legitimar la lógica de maximización de ganancias centrada en la calidad del servicio como principal variable de ajuste, que había caracterizado la prestación de los servicios en los años previos (Pérez; 2013). Esta legitimación se realizó mediante la instalación de una explicación monocausal, plasmada en el decreto de Emergencia Ferroviaria, que hacía depender el deterioro de la red de la responsabilidad unilateral del Estado, que en el marco el agravamiento de la crisis que finalizó con el reemplazo del modelo de Convertibilidad, acumuló una deuda con los concesionarios que afectó la posibilidad de prestar los servicios bajo los estándares acordados en los respectivos contratos.

En un contexto de tarifas congeladas, suspensión de los planes de inversión y supresión de los estímulos que habían existido para mejorar los servicios, el sostenimiento del sistema pasó a depender casi exclusivamente de los subsidios del Estado. Como medida adicional, un día antes del traspaso de la presidencia y como resultante de la nueva estructura de costos derivada de la modificación del tipo de cambio, el gobierno saliente del presidente Duhalde reestructuró los criterios de cálculo para el otorgamiento de los subsidios a los concesionarios de la red, prácticamente delegando en los concesionarios la determinación de sus montos. Hasta el año 2003 la suma de esta compensación había dependido de la cantidad de pasajeros transportados por cada grupo empresario y de lo recaudado por la tasa sobre el gasoil, pero a partir de esa decisión el criterio de cantidad de pasajeros fue reemplazado por el de costos de explotación que pudiera justificar cada 
operador (Resolución 126/2003).

En parte como resultante de los procesos anteriores, el período iniciado en 2003 estuvo caracterizado por un incremento continuo de las transferencias directas del Estado hacia los concesionarios de la red, con el objeto de sostener la prestación de los servicios. Durante dicho período los subsidios se convirtieron en la principal fuente de ingresos de los operadores privados, llegando a representar el $80 \%$ de los mismos. Como se observa en el gráfico que se presenta a continuación, entre los años 2003 y 2010, los ingresos de estos en concepto de tarifas crecieron un $75 \%$, mientras que los provenientes de subsidios estatales lo hicieron en más de un $2.000 \%$.

\section{Gráfico $\mathrm{N}^{\circ} 2$}

Evolución del monto de las tarifas y los subsidios operativos de los ferrocarriles del Área Metropolitana de Buenos Aires (AMBA) entre 2003 y 2010.

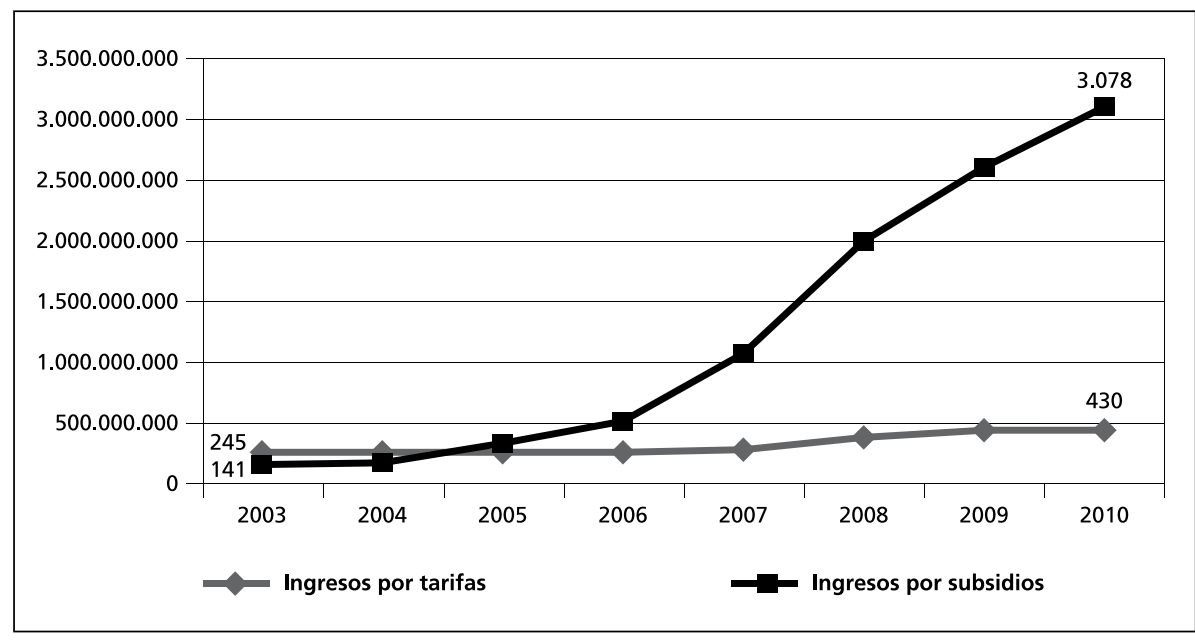

Fuente: Elaboración propia a partir de datos de UNSAM-ITF, 2013.

Con posterioridad a 2010 la tendencia creciente del monto de las transferencias estatales para el sostenimiento de la red se mantuvo. Según un informe de la Auditoría General de la Nación (2014), en el año 2012 los subsidios recibidos por los operadores de la red habían alcanzado los 4.708 millones de pesos. Cabe resaltar que el incremento de estas transferencias superó el que tuvieron los costos salariales, principal destino de las mismas, pues mientras los salarios al personal del sector transporte se multiplicaron por 4 entre 2005 y 2012, los subsidios a las concesionarias crecieron 9 veces (AGN, 2014).

Sin embargo, el éxito de una política no depende sólo de la orientación del Estado, que en este caso se materializó vía la transferencia directa de recursos, sino, entre otros fac- 
tores, de la calidad de la intervención estatal, la cual atañe tanto a una dimensión interna (capacidades y recursos) como externa o relacional. Esta última, refiere tanto el grado de autonomía del Estado con relación a la formulación, implementación y monitoreo de políticas, como a la vinculación que establece con los actores sociales que participan del ámbito de aplicación de dicha política (Castellani y Llampart; 2012). Sobre este último aspecto versarán las secciones siguientes.

\section{Nuevos modelos de gestión para los ferrocarriles metropolitanos}

A partir del año 2003 se abrió un período de progresivas transformaciones en la forma de organizar socialmente la prestación de los servicios ferroviarios de pasajeros del AMBA. Las mismas permitieron observar un progresivo protagonismo del Estado en la actividad, no exento de tensiones. Un análisis sobre los determinantes principales que llevaron a la implementación de las reformas sobre el sistema, permite identificar al menos tres niveles de procesos que impactaron heterogéneamente en el carácter que finalmente asumió dicha transformación.

El primero de ellos puede situarse en un nivel que trasciende el ámbito más acotado en el que se desarrolla la prestación de los servicios ferroviarios de pasajeros, pero que sin duda impactó sobre la forma y resultantes de las reformas implementadas. El mismo refiere a la situación en que se encontraba la Argentina a inicios del siglo XXI y a la fuerza social con la que asumió el nuevo gobierno del Estado.

El gobierno que asumió en 2003 debió enfrentar el desafio de ampliar los márgenes de autonomía relativa del Estado respecto de los intereses de los sectores más concentrados de las clases dominantes. Si bien esta meta fue lográndose progresivamente a medida que el gobierno avanzaba en la implementación de un conjunto de medidas dirigidas a alcanzarla, construir las condiciones de gobernabilidad para prosperar en esa dirección constituyó un prerrequisito para una fuerza política que había asumido con el $22 \%$ de los votos. Esta condición inicial de relativa debilidad fue revertida paulatinamente a partir de la construcción de un amplio abanico de alianzas con distintos sectores económicos, políticos y sociales que se desarrolló bajo el símbolo de la "transversalidad”. Dicho contexto político constituyó el punto de origen de la alianza gobierno-sindicatos (Ecthemendy; 2013) y el marco bajo el cual cada una de las Subsecretarías modales de transporte fue ocupada por un representante del sector sindical (Barbero y Bertranou; 2014).

En 2006 el gobierno designó al frente de la Subsecretaría de Transporte Ferroviario a Antonio Luna, un conductor de locomotoras diésel asociado al sindicato La Fraternidad, que se desempeñaba desde el año 1996 como Secretario de Política Ferroviaria del Consejo Directivo de dicho sindicato. Posteriormente, en el año 2008, las presidencias de las dos empresas estatales creadas por el Estado en el marco de la Ley de Re- 
ordenamiento Ferroviario (Ley 23.652) -la Sociedad Operadora Ferroviaria Sociedad del Estado (SOFSE) y la Administradora de Infraestructura Ferroviaria (ADIF)-, serían ocupadas por representantes de La Fraternidad y la Unión Ferroviaria (los principales sindicatos ferroviarios). ${ }^{2}$ Finalmente, este sector también tuvo un lugar central cuando luego de la rescisión de los contratos a algunas empresas, se puso en marcha un nuevo modelo para la prestación de los servicios ferroviarios: las Unidades de Gestión Operativas Ferroviarias de Emergencia (UGOFE). Bajo este esquema, fracciones de sindicalistas pasaron a tener una gravitación central en un modelo que implicó una mayor hibridación o interpenetración de lógicas (Wright; 2010), al sumar nuevas prácticas de reproducción de poder a su dinámica de funcionamiento. Debido a su centralidad en la lógica de desenvolvimiento del modelo, las mismas serán analizadas con mayor detalle en el siguiente apartado.

El segundo de los procesos que propició transformaciones en la forma de organizar socialmente la prestación de los servicios, estuvo ligado a las continuas perturbaciones del sistema (García; 2006) referidas tanto a la inestabilidad en las condiciones de su oferta (interrupciones, demoras y accidentes recurrentes, algunos de gran envergadura) como a la emergencia de diversas expresiones de disconformidad protagonizados por pasajeros que asumieron la forma de violencia colectiva y entre las cuales destacaron episodios de gran envergadura que se convirtieron en verdaderos estallidos de hostilidad (Pérez;2013).

Hasta mediados de 2004 el gobierno no implementó ninguna reforma sobre el sistema ferroviario y mantuvo el esquema de concesión en las siete líneas metropolitanas. Hasta entonces las líneas Sarmiento y Mitre estaban a cargo del concesionario Trenes de Buenos Aires (Grupo Cirigliano), las líneas Roca, San Martín y Belgrano Sur, bajo responsabilidad del concesionario Metropolitano (Grupo Metropolitano), mientras que la línea Urquiza dependía de Metrovías (Grupo Roggio) y la línea Belgrano Norte de Ferrovías (Grupo EMEPA).

En el marco de dicha forma de organizar socialmente la prestación de los servicios, basada en un híbrido (Wright; 2010) de carácter capitalista-estatal, ${ }^{3}$ la década de 1990 había gestado un modelo con fuerte predominio de una lógica de maximización de ganancias centrada en el recorte de gastos operativos y de inversión y en el uso discrecional de los recursos públicos por parte de los concesionarios que explotaban la red (Pérez 2013, 2014). El profundo deterioro que el despliegue de dicha lógica implicó para la calidad de los servicios coadyuvó a que a partir de 2003, como resultado de repetidas perturbaciones que asumieron la forma de demoras y cancelaciones, se sumaran expresiones de disconformidad protagonizadas por pasajeros. Las que adquirieron carácter de violencia colectiva fueron leídas como señal de peligro (Coser; 1970) y contribuyeron a que el gobierno implementara un conjunto de tácticas tendientes a resolver las deficiencias de las prestaciones (Pérez; 2013). 
En 2004, luego de una serie de accidentes fatales y manifestaciones de descontento de los pasajeros, el gobierno decidió quitarle al concesionario Metropolitano la explotación de la línea San Martín. El extremo deterioro del servicio quedó expresado en el decreto rescisorio ( $\left.N^{\circ} 798 / 2004\right)$, que especificó los tipos de incumplimientos detectados: impuntualidad, falta de confort, oferta de servicios, mantenimiento del material rodante y de tracción. En referencia a este último punto, se señaló que en el momento de la revocación del contrato se encontraba en servicio apenas el 20\% del material de tracción entregado en concesión. La responsabilidad sobre dicha línea se transfirió a una Unidad de Gestión Operativa Ferroviaria de Emergencia (UGOFE), conformada por el resto de los concesionarios de la red (Metrovías, Ferrovías y Trenes de Buenos Aires). Posteriormente, en el año 2007, se cancelaron los restantes contratos con dicho concesionario (líneas Roca y Belgrano Sur), luego de que ocurriera un estallido de hostilidad (Pérez; 2013) protagonizado por pasajeros, en una de las cabeceras terminales más importantes de la red. ${ }^{4}$ Estas líneas de servicios fueron transferidas, al igual que había ocurrido en el año 2004, a la UGOFE.

La nueva forma de organizar socialmente la prestación de los servicios en las líneas que quedaron a cargo de UGOFE implicó cambios respecto a la etapa precedente. En términos generales significó un avance del Estado en la actividad, ya que los concesionarios pasaron a operar los servicios por cuenta y orden del Estado Nacional cobrando un monto por su gerenciamiento. La promulgación de la Ley de Reordenamiento Ferroviario en 2008 intentó un mayor ordenamiento de la actividad, con la creación de dos empresas estatales que asumieron una, la operación de los servicios (SOFSE) y la otra, la administración de la infraestructura ferroviaria (ADIF). No obstante, la implementación del nuevo modelo abarcó sólo a las líneas en las cuales se cancelaron los contratos de concesión, mientras que el resto (Sarmiento, Mitre, Belgrano Norte y Urquiza) continuaron funcionando bajo el modelo heredado de la década de 1990.

Finalmente, el tercero de los procesos que en la hipótesis que aquí se sostiene impactó sobre el sistema, ya no como desencadenante de transformaciones sino como uno de los elementos centrales que funcionan como clave explicativa para entender la lógica específica que asumieron las mismas, refiere a una dimensión señalada por Wright (2010) acerca del tipo de proyectos de cambio o transformación que emprenden los sectores con responsabilidad sobre dicho sistema. Este señalamiento implica considerar las culturas empresariales y sindicales operantes en los modelos de gestión de los servicios, en su articulación con las lógicas desplegadas por los sectores del Estado que participaron de la actividad. Observar el entramado de lógicas en acción que se desplegaron bajo el nuevo modelo de prestación de los servicios y las que tuvieron lugar en el resto de las líneas, permite desentrañar cuál fue el carácter dominante que asumió la prestación de los servicios ferroviarios de pasajeros durante esta etapa. 


\section{El carácter dominante de un nuevo híbrido social}

Como se ha mencionado, el modelo de UGOFE significó un cambio respecto a las concesiones, en tanto las empresas que se hicieron cargo de los servicios en las líneas cuyos contratos habían sido cancelados, comenzaron a operar los servicios por cuenta y orden del Estado Nacional. En este esquema, los ingresos de los concesionarios pasaron a depender casi exclusivamente de las transferencias estatales, calculadas sobre la base de un porcentaje de las compensaciones por costos de explotación y de otros fondos que la Secretaría de Transporte dispuso para el mantenimiento de los servicios (González Badián y Gentili; 2012). Dado que los costos de explotación incluían la subcontratación de empresas para la realización de tareas a cargo de UGOFE, se intensificó la orientación de los operadores hacia sus proveedores (Barbero y Bertranou; 2014), los cuales a su vez, eran empresas propiedad de los mismos grupos que controlaban la red. ${ }^{5}$ Dicha orientación no sólo fue observable en el comportamiento de los grupos empresarios, sino que implicó a las fracciones de sindicalistas que participaron directamente del modelo, como se verá seguidamente.

El otro rasgo sobresaliente del modelo de UGOFE fue la lógica de acumulación de poder desplegada por las fracciones de sindicalistas que participaron del negocio. $\mathrm{Si}$, como sostiene Wright (2006), la posibilidad de morigerar el poder del capital depende en parte de la creación de dispositivos institucionales, entre los cuales destacan los acuerdos neocorporativistas tripartitos en los cuales las organizaciones sindicales, las asociaciones patronales y el Estado negocian ciertas regulaciones económicas, el caso bajo estudio instala algunas tensiones. Si bien el aumento del poder sindical en el sector tuvo algunos efectos positivos para los trabajadores ferroviarios sindicalizados, en particular en lo que concierne al incremento del nivel salarial, que fue del orden del $800 \%$ durante el período (ITF-UNSA, 2013) -porcentaje que se encuentra muy por encima del que tuvieron los trabajadores de otras actividades-, no debe dejar de observarse el principio de exclusión que se ejerció para con otros conjuntos de trabajadores.

En el marco de su participación directa en el modelo de gestión ferroviaria, como mediador entre la empresa y el Estado en la contratación de trabajadores, ${ }^{6}$ el sindicalismo empresario ${ }^{7}$ desarrolló una política de subcontratación que, análogamente a la implementada por los concesionarios, se llevó a cabo con empresas vinculadas a representantes sindicales, entre los que destacaron aquellas vinculadas al líder de la Unión Ferroviaria, José Pedraza. ${ }^{8}$ En dichas empresas, los trabajadores contratados cobraban montos inferiores a los fijados por el convenio del sector, realizando iguales tareas que aquellos que se encontraban amparados por el convenio. Investigaciones judiciales abiertas han detectado que esta diferencia fue apropiada por el sindicalismo empresario, en connivencia con personal de la UGOFE (CELS, 2012:294). 
No obstante, la significación atribuida al comportamiento asumido por los grupos de sindicalistas que participaron del negocio ferroviario en esta etapa, no debiera simplificarse a la simple consideración de sus intereses económicos. Las prácticas desplegadas implicaron un eficiente mecanismo de control de poder sindical. Considérese a este respecto que hasta el mes de octubre de 2010 , los ingresos a planta permanente a la empresa y las recategorizaciones eran controladas por la cúpula de la Unión Ferroviaria en connivencia con los directivos de la UGOFE. De modo que impedir el pase a planta de los trabajadores subcontratados era fundamental ya que podría haber puesto en riesgo no sólo su poder económico sino también su poder político. Finalmente, cabe resaltar que quien giraba los fondos para el pago de los costos operativos del sector (incluidos salarios de trabajadores), era el Subsecretario de Transporte Ferroviario, Antonio Luna, relacionado según ya se señaló con el sindicato La Fraternidad. Dicha articulación lleva a analizar qué tipo de proyecto desarrolló el Estado en el ámbito del sector ferroviario.

En particular, el marco político institucional en el que se desarrolló la actividad durante este período aporta elementos para comprender el contexto operacional de los actores del sistema. Investigaciones judiciales y periodísticas abiertas han asociado el accionar de la Secretaría de Transporte con la función de recaudación de fondos para sostener la necesidad de reproducción político-partidaria del gobierno nacional (Barbero y Bertranou; 2014). Al respecto destacan las denuncias que pesan sobre quien fuera Secretario de Transporte entre 2003 y 2009, Ricardo Jaime, tanto por enriquecimiento ilícito como por incumplimiento de los deberes de funcionario público.

El entramado de relaciones entre los sectores del Estado con responsabilidad sobre los servicios, las empresas concesionarias y el sindicalismo empresario, pasó a ser un tema central en el modelo de UGOFE. El caso que visibilizó cuál fue el carácter de dichas relaciones sucedió el 20 de octubre de 2010 cuando un grupo de choque que respondía al gremio Unión Ferroviaria, con complicidad de funcionarios de la policía federal, atacó con armas de fuego a trabajadores subcontratados de la línea Roca que, con apoyo de militantes de partidos de izquierda, reclamaban su incorporación a la planta permanente de la empresa y la reincorporación de trabajadores despedidos. Dicho ataque dejó como saldo un muerto y tres heridos de gravedad. Los avances judiciales en dicha investigación pusieron en evidencia una compleja trama de relaciones entre diferentes esferas del poder del sindicalismo, de la empresa, de la policía y del poder político (CELS 2012:297).

El análisis de la dinámica del sistema durante el período tensiona el uso de algunos de los conceptos utilizados por la llamada nueva sociología del desarrollo, forjados para explicar el derrotero de las políticas públicas basadas en subsidios estatales. En particular, los conceptos de reciprocidad (Amsden 1989) y autonomía enraizada (Evans; 1996), no permiten captar la compleja trama de relaciones que estructuran el fenómeno bajo 
estudio. Recordemos que el primero refiere a una relación en la cual el Estado subsidia a las empresas pero a cambio exige el cumplimiento de ciertas normas de desempeño, mientras que el segundo describe una situación en la cual los burócratas mantienen lazos estrechos con las empresas pero aun así son capaces de formular sus preferencias en forma autónoma (Schneider; 1999: 49).

En el primer caso, ninguna de las condiciones de la reciprocidad se cumplió durante el período, a saber: 1) claridad en las normas de desempeño, 2) supervisión por parte de la autoridad estatal, 3) capacidad de aplicar sanciones y por último, 4) existencia de acciones tendientes a asegurar la probidad del Estado (Schneider; 1999:53). Ahora bien, en la hipótesis de este trabajo la ausencia de reciprocidad no radicó en un problema de debilidad o ausencia de capacidades estatales, pues como se ha mostrado en otro trabajo (Pérez y Rocca; 2015) algunos mecanismos de control fueron fortalecidos, sino que respondió a un tipo de interacción entre los actores del sistema donde operó un principio de intercambio económico realizado con base a necesidades que trasvasaron las derivadas del sector de actividad en cuestión. Aquí, los objetos intercambiados sirvieron a los fines de acumulación de poder político y/o económico, según el actor que se esté analizando.

En lo que refiere a la autonomía enraizada, el caso muestra que efectivamente este rasgo estuvo presente y sin embargo, no garantizó un desempeño virtuoso del sector. Durante la etapa posterior a 2003 fue posible observar un Estado que mantiene estrechos lazos con los empresarios y sindicalistas ferroviarios; se ha mencionado sin embargo que el carácter de dicha relación tendió a apropiar los recursos del sistema en función de objetivos ajenos al sector, que encontraron en el mismo un espacio propicio para su desenvolvimiento. En la hipótesis que aquí se sostiene, fue justamente el mayor enraizamiento el que permitió a los funcionarios de gobierno implementar un mecanismo de acumulación de poder que resultó, por el tiempo que duró, provechoso para todos los sectores que participaron. En tal sentido y como intento de caracterizar de manera más rigurosa la relación que se fue configurando en este ámbito, se propone la hipótesis de simbiosis entre los términos de la relación (Estado-empresarios-sindicalismo empresario) pero colusiva, ya que los acuerdos de partes resultaron beneficiosos para los sectores que participaron, pero perjudiciales para terceros, en particular para los pasajeros que se vieron privados de acceder a un servicio que funcione correctamente y, en última instancia, para la sociedad en su conjunto, que soportó una mayor presión impositiva ${ }^{9}$ y/o reasignación de recursos en función de sostener el funcionamiento de los ferrocarriles metropolitanos.

Si se considera el sistema ferroviario metropolitano tomado en su conjunto, el mismo no mostró ninguna coherencia funcional durante esta etapa. En él convivieron distintos esquemas de gestión: el modelo UGOFE en las líneas Roca, Belgrano Sur y San Martín y el heredado de la década previa, con concesiones en las líneas Belgrano Norte, 
Urquiza, Sarmiento, Mitre. Hacia el final del período que abarca este trabajo, estas dos últimas líneas también fueron transferidas a una unidad de gestión operativa de emergencia, como resultante de profundas perturbaciones del sistema derivadas de la lógica dominante que asumió su prestación.

En el mes de febrero del año 2012 un trágico suceso ocurrido en la estación terminal de Once, ${ }^{10}$ arrojó decenas de víctimas fatales y evidenció, una vez más, cuál era la lógica dominante de funcionamiento del servicio en la empresa capitalista estatal: la maximización de ganancias de los concesionarios privados realizada con base en el recorte de gastos operativos y de inversión, ${ }^{11}$ viabilizada por un estado de simbiosis colusiva entre Estado y empresarios del sector. Inicialmente la línea fue intervenida, mientras se desarrollaban investigaciones tendientes a determinar las causas del hecho. Pasaron unos meses hasta que el gobierno tomó la decisión de rescindir el contrato al concesionario Trenes de Buenos Aires. Para la operación de las líneas que estaban a su cargo, Mitre y Sarmiento, se creó una nueva Unidad de Gestión Operativa (UGOMS) conformada por los concesionarios sobrevivientes, Metrovías y Ferrovías. Hacia fines del año 2012, la operación del sistema ferroviario de pasajeros en el AMBA quedó concentrada en manos de estos dos concesionarios, los cuales tenían a su cargo, bajo diversas modalidades de gestión, todas las líneas de ferrocarriles de pasajeros del área metropolitana de Buenos Aires.

\section{La aceleración en el ritmo de los cambios}

Las recurrentes perturbaciones del sistema ferroviario que incluyeron desde accidentes con víctimas fatales producto del deterioro de la red, hasta medidas de fuerza protagonizadas por trabajadores precarizados que afectaron recurrentemente el espacio de realización del servicio, tuvieron un rol destacado en el camino hacia la peculiar estatización del mismo. Articulado a ellas, se produjo la determinación gubernamental de avanzar hacia un mayor control del sistema que involucró una redefinición de las alianzas preexistentes. Asimismo, el proceso político abierto con un horizonte electoral ${ }^{12}$ cada vez más cercano, impactó también en el ritmo y orientación de los cambios.

Sin dudas y en parte por el fuerte impacto mediático que generó, el caso de Once fue el que inauguró un período de numerosas transformaciones en el sector ferroviario. Una cronología de las principales medidas permite observar la intensidad en el ritmo de las mismas.

En junio 2012 la Secretaría de Transporte fue transferida al ámbito del Ministerio del Interior, que pasó a llamarse Ministerio del Interior y Transporte. La medida reveló la determinación de jerarquizar el área y desplazar a algunos de los actores que habían tenido importante gravitación en la lógica que había signado el modelo ferroviario 
en los años precedentes. El primer desplazamiento, en el mes de septiembre de dicho año, fue el de quien había sido el principal responsable de la Subsecretaría de Transporte, Antonio Luna.

En junio 2013 se estableció un régimen de penalidades por incumplimientos contractuales para los servicios ferroviarios operados por las distintas Unidades de Gestión Operativas (Resolución 511/2013) inexistente hasta la fecha. Estas unidades, en particular las responsables de la operación de los servicios en las líneas Roca, San Martín y Belgrano Sur, habían funcionado sin ningún instrumento de control estatal por más de seis años.

Un mes más tarde, como resultado de un paro sorpresivo de los maquinistas en rechazo a un mayor control hacia los mismos (el Ministro había anunciado la instalación de cámaras en las cabinas de conducción) y de incidentes que se produjeron en el marco de dicha medida, (destrozos provocados por un grupo de personas en la estación terminal de Constitución), el gobierno denunció ante la justicia al Secretario General del gremio La Fraternidad (Omar Maturano) y desplazó de la presidencia de ADIF a José NicanorVillafañe, también miembro de dicho sindicato. En octubre, fue apartado de la presidencia de la SOFSE (la otra empresa estatal creada por la Ley de Reordenamiento Ferroviario) Juan Araya, relacionado al sindicato Unión Ferroviaria.

En este lapso, otros dos sucesos en la línea Sarmiento, ${ }^{13}$ uno de los cuales arrojó nuevamente víctimas fatales y ambos ligados al pésimo funcionamiento del servicio, actuaron para que finalmente el gobierno decidiera reestatizar la línea, hecho que ocurrió el 24 de octubre de 2013. Contrariamente al ánimo estatizante que desde diversos sectores se le atribuyó a la fuerza que conducía el gobierno del Estado, la decisión de re-estatización no constituyó una estrategia generalizada sino una táctica parcial y limitada frente a los desequilibrios del sistema. Las seis líneas de servicios restantes continuaron siendo operadas con los modelos de gestión preexistentes, aunque por un breve lapso.

En febrero 2014 se disolvieron las Unidades de Gestión Operativas de Emergencia y se reestructuraron los contratos de prestación de los servicios con los operadores privados subsistentes. Los nuevos contratos implicaron un mayor ordenamiento de la actividad, incluyeron esquemas de premios y penalidades detallados con metas de frecuencia, limpieza y recaudación. El grupo Roggio asumió el gerenciamiento de las líneas Mitre y San Martín y el grupo EMEPA, el Roca y el Belgrano Sur. Mientras tanto, las líneas Urquiza (Roggio) y Belgrano Norte (EMEPA), continuaron siendo operadas bajo el modelo de concesión heredado de la década de los años noventa.

Hacia fines de 2014 el sistema mostró signos de mayor ordenamiento, aunque considerado en su conjunto destacaba su incoherencia funcional. Cuatro líneas funcionaban bajo el modelo de gerenciamiento, dos bajo el de concesiones y una línea se encontraba estatizada. 
El intenso ritmo de cambios que en el lapso de apenas dos años (entre febrero de 2012 y diciembre de 2014) afectaron las formas de organizar socialmente la prestación de los servicios ferroviarios de pasajeros en el AMBA, no respondieron a una planificación estratégica dirigida a superar las deficiencias que la dinámica de las distintas operaciones había gestado sino, más bien, a tácticas puntuales de resolución de problemas. En igual dirección, el creciente esfuerzo económico dirigido a recuperar años de sostenido deterioro, que en este período se realizó a través de la compra de material rodante y de cuantiosas inversiones en infraestructura, además de los importantes subsidios del Estado para sostener la operación de los servicios, no deja dudas acerca de su eficacia, sin embargo cabe recordar que eficacia no es lo mismo que eficiencia y en este sentido, la ausencia de una mirada estratégica sobre el sector podría constituirse en un obstáculo que acarree nuevos problemas.

\section{El Estado en funciones empresariales}

En abril 2015 el Congreso Nacional aprobó la Ley de Ferrocarriles Argentinos. El proyecto planteó como objetivo la "recuperación definitiva de la administración de los ferrocarriles por parte del Estado, partiendo de la idea central de que el mismo puede gestionar incluso de una manera más eficiente que los privados". La premisa encerró un cambio de paradigma respecto a los postulados que sostuvieron su transferencia a operadores privados a inicios de los años noventa y fue percibida por algunos sectores como una de las pocas veces en que el Estado asumía la iniciativa sin quedar bajo la presión de los acontecimientos (Müller; 2015). Sin embargo, difícilmente pueda soslayarse la cercanía de la contienda electoral que en octubre de 2015 definiría quién sería la nueva fuerza política que conduciría el gobierno del Estado. La experiencia exitosa respecto a la administración de la línea Sarmiento pareció ser también un factor que incentivó la decisión, al demostrar, según expresiones de la Presidenta de la Nación, una mejor gestión del Estado respecto a los empresarios privados, reflejada en el aumento de costos que tuvieron las líneas operadas por éstos, en comparación con la administrada por el Estado. ${ }^{14}$

Considerada en su contenido y en lo que a los trenes metropolitanos respecta, la flamante ley constituyó un reordenamiento del sistema y un reconocimiento de las responsabilidades que ya asumía el Estado, más que una estatización plena. Los aspectos destacados fueron los siguientes: por un lado, los operadores privados ya operaban los servicios por cuenta y orden del Estado Nacional en cinco de las siete líneas de servicios. Esto se mantuvo con la nueva ley, en la que se dispuso que la Operadora Ferroviaria Sociedad del Estado (SOFSE) “tendrá a su cargo la prestación de los servicios de transporte ferroviario de pasajeros en todas sus formas, que le sean asignados, incluyendo el material rodante, el mantenimiento de la infraestructura ferroviaria que utilice para la operación (...) y la gestión del sistema de circulación de trenes”. Estos dos últimos puntos constituyeron una novedad para la SOFSE, ya que el mantenimiento de la infraestructura 
era competencia de la ADIF y la gestión de circulación de los trenes responsabilidad de los privados. En este sentido, la ley reorganizó la actividad evitando superposición de funciones entre empresas del Estado.

Por otra parte, la ley dejó abierta la participación de operadores privados, ya que propuso que el Estado asumiría la prestación de los servicios "por sí, por intermedio de terceros, o asociado a terceros", y lo habilitó a renegociar los contratos con las empresas que ya se encontraban operando los servicios.

Finalmente, se procedió a la construcción de un nuevo organigrama institucional que se materializó con la creación de Ferrocarriles Argentinos Sociedad del Estado, bajo la órbita del Ministerio del Interior y Transporte. Esta empresa pasó a ser sociedad controlante de las dos empresas estatales creadas por la Ley de Reordenamiento Ferroviario en 2008, SOFSE (operadora) y ADIF (administradora de infraestructura).

Hay que resaltar dos cuestiones respecto a la implementación del modelo. Según refiere la ley, el mismo se asimila "al instaurado en la República Francesa, en donde se ha procedido a reunificar el sistema ferroviario de ese país, poniéndolo a cargo de la SNCF (Societé Nationale des Chemins de Fer), convertida en un gran holding ferroviario público, en cuyo interior funcionan dos nuevas divisiones, SNCF Mobilités (operadora) y SNCF Réseau (infraestructura)". La experiencia fallida con relación al modelo UGOFE, cuyo esquema fue tomado del europeo, instala la necesidad de atender los riesgos que muchas veces acarrean los monocultivos institucionales. Como bien sostienen Acuña y Chudnovsky (2013: 29) las instituciones no operan aisladas de la materialidad de lo social. Los éxitos que alcanzan determinadas políticas en un espacio social, pueden derivar en fracasos cuando se los implementa en otro con características estructurales diferentes.

La siguiente cuestión refiere nuevamente a las lógicas que se despliegan al interior de las instituciones, más allá de las reglas formales que moldean los comportamientos que se desarrollan al interior de las mismas. La propuesta de articulación institucional que propuso la nueva ley, entre sectores cuyas lógicas de acumulación de poder dependen de prácticas sociales divergentes,${ }^{15}$ instala siempre el desafio de cómo equilibrar intereses muchas veces contrapuestos. En tal sentido, no cabe duda que las transformaciones de la última etapa en el sistema bajo estudio avanzaron hacia una descorporativización del espacio. Sin embargo, la continuidad de los logros alcanzados requerirá un esfuerzo continuo en esta dirección que dependerá, entre otros factores, de la orientación que tome la fuerza social que asuma el gobierno del Estado en diciembre de 2015. 


\section{Reflexiones finales}

Los últimos años han significado para los ferrocarriles metropolitanos un período de intensas transformaciones en las formas sociales de organizar su prestación. Estos cambios respondieron, como rasgo dominante, a profundas perturbaciones del sistema, resultantes de lógicas de acumulación de poder que encontraron en este espacio uno propicio para su desenvolvimiento. El rasgo del período fue el progresivo avance del control estatal en la actividad, en el marco de un clima general de revalorización del rol del Estado en la economía. Los resultados iniciales de esta mayor intervención profundizaron los rasgos más regresivos que había asumido el sistema en la etapa precedente, sumando nuevas perturbaciones a las ya existentes.

En el marco de una reorientación en las formas de concebir la función social del sistema ferroviario de pasajeros, no ajena al impacto que produjo la muerte de decenas de personas luego del accidente de Once y al ritmo de las confrontaciones del período, el Estado fue adquiriendo progresivamente un mayor control sobre la actividad, con mejores resultados que los que había obtenido en el período anterior.

Una periodización de los cambios producidos en la formas sociales de organizar la prestación de los servicios, realizada a partir del estudio de las dinámicas sociales, políticas y económicas que se desarrollaron en el marco de dicho sistema, en articulación con cambiantes condiciones de contorno (García; 2006), hace observable que el éxito de una mayor intervención estatal depende, entre otros factores, de qué tipo de proyectos de cambio y transformación asuman los responsables de intervenir sobre la política pública en cuestión y que el Estado, es también el estado de las relaciones de fuerzas en un momento determinado. 


\begin{abstract}
${ }^{1}$ Este artículo recoge parte de los resultados de la investigación titulada Obstáculos y potencialidades en las formas de organizar socialmente la prestación de los servicios ferroviarios de pasajeros del área metropolitana de Buenos Aires (2003-2015), financiada por el Consejo Nacional de Investigaciones Científicas y Técnicas (CONICET) en el marco de mi beca posdoctoral. Asimismo, forma parte de los resultados parciales del proyecto UBACyT, 2013-2016, Transporte Público y conflicto social: El caso del sistema ferroviario de pasajeros del área metropolitana de Buenos Aires, con sede en el Instituto de Investigaciones Gino Germani, Facultad de Ciencias Sociales, UBA.

${ }^{2}$ La ADIF fue ocupada por un miembro de la comisión directiva de La Fraternidad, José Nicanor Villafañe, mientras que la Presidencia de la SOFSE, fue asignada a Juan Araya, ligado al sindicato Unión Ferroviaria.

3 “"[En estas empresas] el Estado es dueño de algunos medios de producción pero todavía hay un mercado libre para la fuerza de trabajo y los bienes. Como resultado de ello, el modo de explotación sigue siendo sustancialmente capitalista, girando en torno a la diferencia entre el valor de la fuerza de trabajo y el valor de los bienes que se producen en las empresas capitalistas estatales. Pero hay una modificación crucial: como el Estado es propietario de las empresas y por lo tanto no se rige completamente por los imperativos de la competencia comercial, la explotación directa de los trabajadores (...) se suplementa sistemáticamente mediante la explotación impositiva. Las empresas estatales no tienen que producir ganancias y por lo tanto es posible que el valor de los bienes que produzcan sea igual o menor al valor de la fuerza de trabajo empleada. Por ello puede que la explotación mediante los impuestos provea la compensación necesaria (Wright, 2010: 200).

${ }^{4}$ El hecho sucedió en la estación terminal de Constitución de la línea Roca, el 20 de mayo de 2007. En esta oportunidad grupos de pasajeros destrozaron las instalaciones de la estación y se enfrentaron durante horas con la policía.

${ }^{5}$ Entre las empresas con contratos más altos para la reparación de vías en la línea Roca, controlada por UGOFE, figuraba Sehos del grupo Roggio y Herso, del grupo Ferrovías.

${ }^{6}$ Bajo el modelo UGOFE la relación específica que se estableció entre trabajadores, sindicatos y empresas fue la siguiente: los sindicatos postulaban determinados candidatos a ser incorporados ante la empresa, ésta los incorporaba y el Estado les pagaba el sueldo

${ }^{7}$ Este concepto refiere a sectores de la dirigencia sindical que apoyaron procesos de subcontratación y flexibilización laboral fomentando la desmovilización de la clase trabajadora y que promovieron cambios profundos en la actividad de los sindicatos. Entre estos cambios se destaca el asumir empresas a su cargo (Basualdo 2012).
\end{abstract}

${ }^{8}$ José Pedraza es uno de los emblemas de la transformación en la orientación de las representaciones sindicales durante los 90. En esa década estuvo vinculado a la creación y dirección de cooperativas que prestaban servicios como empresas subcontratadas, presidiendo los consejos de Administración de Talleres Mecánica Belgrano Cooperativa de Trabajo Limitada y de la Cooperativa de Trabajo Ferroviaria Unión Limitada (Basualdo y Morales, 2014: 171).

${ }^{9}$ Durante los últimos años de la década del 90 y comienzos del 2000, el total de recursos tributarios recaudados por la Nación mostraba valores estables cercanos al 17\% del Producto Bruto Interno (PIB). A partir de 2003 se observa un incremento sostenido de este indicador, representando hacia el año 2012 un 31.2\% del PIB (Ministerio de Economía y Finanzas Públicas, 2012)

${ }^{10}$ El hecho se produjo el 22 de febrero cuando un tren chocó contra el paragolpes de la estación dejando como saldo 51 víctimas fatales y más de 700 heridos.

${ }^{11}$ Más allá de las imputaciones al maquinista, las investigaciones judiciales apuntaron a que el episodio, producto de la obsoleta infraestructura vial, fue la resultante del desvío de fondos realizado por el concesionario, con complicidad de funcionarios del Estado.

${ }^{12}$ El Ministro del Interior y Transporte, Florencio Randazzo fue precandidato en las elecciones presidenciales de 2015. Finalmente su candidatura no se concretó.

${ }^{13}$ El 13 de junio de 2013 un choque de trenes en la estación Castelar causó la muerte de tres personas y dejó más de 300 heridos. Meses después, el 19 de octubre, un tren chocó contra los paragolpes del andén en la estación terminal de Once, causando decenas de heridos.

${ }^{14}$ En el año 2014 el aumento del gasto de operación para la línea Sarmiento, que administra el Estado, fue del $17 \%$, mientras que los operadores privados aumentaron sus gastos en la línea San Martín, 77 \%; en el Roca, 27\%; en el Belgrano Sur, 56\% y en el Mitre, 51\%. (Revista Apertura, 2 de marzo de 2015).

${ }^{15}$ En el directorio de Ferrocarriles Argentinos se propone la representación del Ministerio del Interior y Transporte, de las empresas SOFSE y ADIF, de la Sociedad Belgrano Cargas y Logística, de los gremios y de los usuarios. 


\section{Referencias bibliográficas}

Acuña, Carlos y Mariana Chudnovsky (2013) “Cómo entender las instituciones y su relación con la política. Lo bueno, lo malo y lo feo de las instituciones y los institucionalismos”. En Carlos Acuña, ¿Cuánto importan las instituciones? Gobierno, Estado y actores en la política argentina. Argentina. Buenos Aires, Siglo XXI:19-70.

Amsden, Alice (1989) Asia's next giant: South Korea and late industrialization. Londres: Oxford University Press.

Antón, Gustavo, Jorge Cresto, Julián Rebón y Rodrigo Salgado (2011). "Una década en disputa. Apuntes sobre las luchas sociales en Argentina". En Massimo Modonesi y Julián Rebón (comps.) Una década en movimiento. Luchas populares en América latina en el amanecer del Siglo XXI. Buenos Aires: Prometeo-CLACSO-UBA, 19-44.

Auditoría General de la Nación (2014) Una década al cuidado de los fondos públicos. Transporte Ferroviario. Informe sectorial del Presidente de la Auditoría General de la Nación. http://leandrodespouy.com/wp-content/uploads/2014/03/Libro-Transporte-Ferroviario.pdf. Descargado el 15 de abril de 2014.

Azpiazu, Daniel (2005). Las privatizadas I y II. Ayer, hoy y mañana. Buenos Aires: Colección Claves para Todos.

Barbero, José y Julián Bertranou (2014) “Una asignatura pendiente. Estado, instituciones y política en el sistema de transporte". Documentos de Trabajo de Estudios sobre el Transporte $\mathbf{N}^{\circ} \mathbf{1}$. Instituto de Transporte. Universidad Nacional de San Martín.

Basualdo, Eduardo (2006) Estudios de Historia Económica Argentina desde mediados del siglo XX a la actualidad. Buenos Aires: FLACSO, Siglo XXI.

Basualdo, Victoria (2012) “Avances y desafios de la clase trabajadora en Argentina de la posconvertibilidad, 2003-2010”. En CELS, Derechos Humanos en Argentina. Informe 2012. Buenos Aires: Siglo XXI, 429-459

Basualdo, Victoria y Diego Morales (2014). La tercerización laboral. Orígenes, impacto $y$ claves para su análisis en América Latina. Buenos Aires: Siglo XXI editores.

Castellani, Ana y Flavia Llampart (2012). "Debates en torno a la calidad de la intervención estatal”. Papeles de Trabajo 6, (9): 155-177. 


\section{Centro de Estudios Legales y Sociales (2012) Derechos Humanos en Argenti- na: Informe 2012. Buenos Aires: Siglo XXI Editores.}

Coser, Louis (1970) Nuevos aportes a la teoría del conflicto social. Buenos Aires: Amorrortu editores.

Costa, Oscar Alberto Luis (2000). "El Impacto del Consenso de Washington en la Transformación Estatal en América Latina y en Argentina". Revista CE 2. 2, 43-54.

Etchemendy, Sebastián (2013) "La "doble alianza" gobierno-sindicatos en el kirchnerismo (2003-2012): orígenes, evidencia y perspectivas”. En Carlos H. Acuña (comp.) ¿Cuánto importan las instituciones? Gobierno, Estado y actores en la política argentina. Buenos Aires: Siglo XXI, 291-324

Evans, Peter (1996) “El Estado como problema y como solución”. Desarrollo Económico 140:529-562.

García, Rolando (2006) Sistemas Complejos. Conceptos, método y fundamentación epistemológica de la investigación interdisciplinaria. Barcelona: Gedisa.

González Badián, Hernán y Rafael Gentili (2012) Los negocios de UGOFE. SA. El vaciamiento de los ferrocarriles metropolitanos. http://www.rafagentili.com.ar/content/uploads/ informe-los-negocios-de-ugofe-062012.pdf. Descargado el 20 de septiembre de 2014.

Instituto de Transporte Ferroviario (2013) Una estrategia para la rehabilitación de los ferrocarriles metropolitanos de Buenos Aires. Foro de discusión sobre el FC suburbano. http:// www.unsam.edu.ar/institutos/transporte/FFCC-Metropolitanos.pdf. Descargado el 10 de mayo de 2014.

Ministerio de Economía y Finanzas Públicas (2012) Informe Económico Nº79, Segundo Trimestre de 2012. Nota Técnica N59. Finanzas Públicas. http://www.economia.gob.ar/peconomica/informe/notas_tecnicas/59\%20NOTA\%20TECNICA\%20 FISCALL\%20INF\%2079.pdf. Descargado el 7 de marzo de 2016.

Müller, Alberto (2015) “Volvió...” Diario Página 12, suplemento Cash, 29 de marzo, pág. 3.

Pérez, Verónica (2014). “Cambios y continuidades en la organización social de los servicios de trenes del área metropolitana de Buenos Aires, Argentina 1990-2010”. Revista Transporte y Territorio, 11: 114-134. 
Pérez, Verónica (2013). Estallidos de hostilidad en el transporte ferroviario de pasajeros del Área Metropolitana de Buenos Aires. 2002-2010. Tesis doctoral en Ciencias Sociales. Universidad de Buenos Aires, Facultad de Ciencias Sociales.

Pérez,Verónica y Mariela Rocca (2015) «Estado y servicios públicos en la posconvertibilidad: ¿qué hay de nuevo en la participación estatal?» XII Congreso Nacional de Ciencia Política Sociedad Argentina de Análisis Político Mendoza, 12 al 15 de agosto de 2015.

Pérez, Verónica y Julián Rebón (2015). "El retorno del Estado.Valoraciones sociales en torno a las empresas estatales". Revista Estudios Sociales. Universidad Nacional del Litoral (a publicarse en 2016).

Polanyi, Karl (2001). La gran transformación. Los orígenes políticos y económicos de nuestro tiempo. México: Fondo de Cultura Económica.

Pucciarelli, Alfredo y Luciana Strauss (2011) "El sinuoso camino del fin: la democracia corporativa en jaque”. Ciencias Sociales 79: 38-43.

Schneider, Ben Ross (1999). "Las relaciones entre el Estado y las empresas y sus consecuencias para el desarrollo. Una revisión de la literatura reciente”. Desarrollo Económico 153: 45-75.

Thwaites Rey, Mabel (2011). "2001-2011 De la crisis a la recomposición social”. Ciencias Sociales 79: 30- 37.

Wright, Erik Olin (2010) Preguntas a la desigualdad: ensayos sobre análisis de Clase, Socialismo y Marxismo. Bogotá: Universidad del Rosario.

Wright, Erik Olin (2006) "Compass points. To points towards socialist alternative". New left review 41: 93-124. 